\title{
Grand challenges in terrestrial microbiology
}

\author{
Lisa Y. Stein ${ }^{1 *}$ and Graeme W. Nicol ${ }^{2 *}$ \\ ' Department of Biological Sciences, University of Alberta, Edmonton, AB, Canada \\ 2 Institute of Biological and Environmental Sciences, University of Aberdeen, Aberdeen, UK \\ *Correspondence: lisa.stein@ualberta.ca; graeme.nicol@abdn.ac.uk
}

Understanding the functional role of different microbial populations is essential to ascertain whether environmental factors affecting their diversity, activity, and physiology will impact the functioning of terrestrial ecosystems. The soil environment represents one of the largest reservoirs of microbes in the biosphere and is the most significant in linking the activity of humans with the interaction and alteration of the major biogeochemical cycles. The global nitrogen cycle has been massively accelerated through the annual removal of over $100 \mathrm{Tg}$ of atmospheric nitrogen for the production and use of fertilizers (Gruber and Galloway, 2008), with the associated production of the greenhouse gas nitrous oxide predicted to be the largest contributor to stratospheric ozone depletion in the twenty-first century (Ravishankara et al., 2009). Global warming is also predicted to have a profound effect on the soil carbon cycle. As permafrost soils contain twice as much carbon as current $\mathrm{CO}_{2}$ levels in the atmosphere, there is great concern that thawing and rapid utilization of carbon "stored" in soil for millennia may result in an accelerated positive feedback to further increase atmospheric $\mathrm{CO}_{2}$ (Schuur et al., 2009). Central to all these processes are the activities of microbes which mediate and control the magnitude of global elemental fluxes. If we are to understand and predict the consequences of accelerating carbon and nitrogen biogeochemical cycles, gaining a fundamental understanding of the role of microbial communities will be critical.

Despite this, we recognize a lack of understanding of fundamental processes that drive, maintain and affect microbial diversity in soil and the role diversity plays in essential soil processes. While we are beginning to understand the scale of extant diversity, we remain largely ignorant of the role and importance of this vast diversity in terms of ecological function. Therefore, a grand challenge of terrestrial microbial ecology is to unambiguously link the structure of microbial communities with their function. The scope of this challenge is quite daunting as next-generation sequencing approaches have revealed an enormous level of diversity and heterogeneity in microbial ecosystems of which only an infinitesimal fraction is represented by cultivated strains. Faced with such tremendous diversity, laboratory studies of model organisms can seem futile. Certainly, there are indisputable issues with using model systems to dissect out and infer the function of particular members of complex populations. The "great plate count anomaly" (Staley and Konopka, 1985) posits that as an upper limit, $1 \%$ of visible microscopic cell counts from most ecosystems are culturable using standard approaches. Furthermore, microorganisms that are relatively easy to cultivate are the "weeds" or fast growers that compete best in an investigator-defined culture medium. Long-term cultivation encourages adaptation to the test-tube, changing the isolates fundamentally from related strains in the environment. Perhaps the biggest issue with cultivation is that pure cultures by definition separate strains from their natural partners, forcing them into an unnatural and often stressful lifestyle. It would seem that given the many issues with cultivation and the functional discontinuity between a pure isolate and a microbial population within a complex community, why bother?

The most obvious answer to this question is that molecular data would be meaningless without a context for gene function. At least one-third of all genomic content remains a functional mystery (Bork, 2000; Galperin and Koonin, 2010) that can perhaps be most easily resolved by studying model organisms and their functional inventory under controlled laboratory conditions. Longmaintained model organisms continue to provide insight to a multitude of basic features including biochemical and structural properties, metabolic pathways, gene regulation, and evolutionary history, and inference from novel genetic and genomic data may identify cultivation strategies for currently uncultivated organisms. Without this basic organismal context, we could never have come so far in understanding the function and regulation of biogeochemical cycles. As we learn more about the potential of microorganisms to transform substrates to and from bioreactive intermediates in the "real world," cultivation is becoming more, not less, of a dire necessity. For instance, the prediction that members of the Thaumarchaeota (Brochier-Armanet et al., 2008) are archaeal ammonia oxidizers was predicted by the retrieval of metagenomic fragments associated with a soil fosmid and a scaffold derived from short shotgun sequenced fragments of archaeal origin from marine water (Venter et al., 2004; Treusch et al., 2005). However, the function of archaeal ammonia oxidizers was validated only by cultivation of Nitrosopumilus maritimus (Könneke et al., 2005) 13 years after 16S rRNA genes of related taxa were found abundant in marine systems.

There are also examples where cultivation of microorganisms based on hypothetical energy-yielding processes (Broda, 1977) can lead to novel ecosystem-level discoveries, the discovery of anaerobic ammonium oxidizing (anammox) bacteria probably being the most famous example (Strous et al., 1999). Another recent example includes the enrichment of Candidatus Methylomirabilis oxyfera, a denitrifying methanotroph (Ettwig et al., 2010) that grows on nitrite and methane under anoxic conditions, and led to the discovery of a novel metabolism of evolutionary significance, the ability to produce $\mathrm{O}_{2}$ internally from nitric oxide dismutation to oxidize methane in the absence of an external $\mathrm{O}_{2}$ source (Ettwig et al., 2010). Without a priori knowledge of the growth conditions of Candidatus M. oxyfera, genome data alone perhaps would have indicated that this organism could, under certain conditions, grow aerobically as a classical methane oxidizer and not necessarily using oxygen generated by itself under otherwise anoxic conditions. This work therefore demonstrates that cultivation in and of itself can 
uncover novel functions and phylotypes, so long as investigators do not limit themselves to "common knowledge."

Although cultivation will continue to be a cornerstone and a grand challenge for the terrestrial microbiology community to live up to, we remain in a rapidly accelerating era of genomic and metagenomic information. Our model organisms can only make so much sense of this information influx. Thus, another set of Grand Challenges to the terrestrial microbiology community involves wise use and application of metagenomic information by understanding how gene annotations are made, stored, and often ignored; continued development of data reduction and statistical tools to make better correlations between genetic data and ecological function; and awareness that functional information usually lags behind pure gene-based information, leading to propagated errors in ascribing putative function to non-validated coding sequences. These challenges are difficult to resolve, but will become more important as we get closer to connecting population structure with ecosystem function in real time and space.

In terrestrial ecosystems, there remains a distinct lack of understanding of how and why the soil environment sustains such a huge amount of microbial diversity. Soil may possess more biological activity and more diversity than any other ecosystem on the planet, with a gram of soil containing up to $10^{6}$ different "species" (Gans et al., 2005). Therefore, for terrestrial microbiologists comes the challenges of understanding the importance of this vast diversity for terrestrial ecosystem functioning, and also what is the relevant scale for studying microbial populations in soil (e.g., from the aggregate to the landscape scale). Current methods typically involve the analysis of genes, transcripts, or genome fragments recovered from soil after removal or in situ extraction of nucleic acids from cells. While these approaches can be appropriate for looking at the extant diversity, any physical association and relative spatial distribution is destroyed, thus making it impossible to understand the importance of microbe interactions such as mutualism, symbioses, and competition. Therefore, future efforts will have to examine microbial communities at the scale of the microbe rather than a few grams to fully appreciate microbially mediated processes in soil. Conversely, larger scales are also appropriate; measuring microbial contributions to pollution (e.g. fertilizer run-off or greenhouse gas emissions) involves consideration at the landscape level. Also, on the basis of bulk soil measurements (and not at the nanometer "microbial" scale), certain community structures can be observed (and predicted) on the basis of relationships with particular physicochemical properties such as $\mathrm{pH}$ (Fierer and Jackson, 2006; Rousk et al., 2010).

We are entering an unprecedented geological epoch where human activities have a profound impact on microbially driven biogeochemical cycles. As terrestrial microbiologists, we are challenged to use all tools at our disposal - from single cell to complex community, from culture to sub-cellular levels, from micron to landscape scales - to understand how the microbial world is responding and eventually stabilizing to a new equilibrium. Our field is poised for a lengthy and illuminating journey.

\section{REFERENCES}

Bork, P. (2000). Powers and pitfalls in sequence analysis: the 70\% hurdle. Genome Res. 10, 398-400.

Brochier-Armanet, C., Boussau, B., Gribaldo, S., and Forterre, P. (2008). Mesophilic crenarchaeota: proposal for a third archaeal phylum, the Thaumarchaeota. Nat. Rev. Microbiol. 6, 245-252.

Broda, E. (1977). Two kinds of lithotrophs missing in nature. Z. Allg. Mikrobiol. 17, 491-493.

Ettwig, K. F., Butler, M. K., Le Paslier, D., Pelletier, E., Mangenot, S., Kuypers, M. M. M., Schreiber, F., Dutilh, B. E., Zedelius, J., De Beer, D., Gloerich, J., Wessels, H. J. C. T., Van Alen, T., Luesken, F., Wu, M. L., Van De Pas-Schoonen, K. T., Op Den Camp, H. J. M., Janssen-Megens, E. M., Francoijs, K.-J., Stunnenberg, H., Weissenbach, J., Jetten, M. S. M., and Strous, M. (2010). Nitrite-driven anaerobic methane oxidation by oxygenic bacteria. Nature $464,543-548$.

Fierer, N., and Jackson, R. B. (2006). The diversity and biogeography of soil bacterial communities. Proc. Natl. Acad. Sci. U.S.A. 103, 626-631.
Galperin, M. Y., and Koonin, E. V. (2010). From complete genome sequence to "complete" understanding? Trends Biotechnol. 28, 398-406.

Gans, J., Wolinsky, M., and Dunbar, J. (2005). Computational improvements reveal great bacterial diversity and high toxicity in soil. Science 309, 1387-1390.

Gruber, N., and Galloway, J. N. (2008). An earth-system perspective of the global nitrogen cycle. Nature 451, 293-296.

Könneke, M., Bernhard, A. E., de la Torre, J. R., Walker, C. B., Waterbury, J. B., and Stahl, D.A. (2005). Isolation of an autotrophic ammonia-oxidizing marine archaeon. Nature 437, 543-546.

Ravishankara, A. R., Daniel, J. S., and Portmann, R. W. (2009). Nitrous oxide $\left(\mathrm{N}_{2} \mathrm{O}\right)$ : the dominant ozonedepleting substance emitted in the 21 st century. Science 326, 123-125.

Rousk, J., Bååth, E., Brookes, P. C., Lauber, C. L., Lozupone, C., Caporaso, J. G., Knight, R., and Fierer, N. (2010). Soil bacterial and fungal communities across a $\mathrm{pH}$ gradient in an arable soil. ISME J. 4, 1340-1351.

Schuur, E. A. G., Vogel, J. G., Crummer, K. G., Lee, H., Sickman, J.O., and Osterkamp, T.E. (2009). The effect of permafrost thaw on old carbon release and net carbon exchange from tundra. Nature 459, 556-559.

Staley, J. T., and Konopka, A. (1985). Measurement of in situ activities of nonphotosynthetic microorganisms in aquatic and terrestrial habitats. Annu. Rev. Microbiol. 39, 321-346.

Strous, M., Fuerst, J. A., Kramer, E. H. M., Logemann, S., Muyzer, G., Van De Pas-Schoonen, K. T., Webb, R., Kuenen, J. G., and Jetten, M. S. M. (1999). Missing lithotroph identified as new planctomycete. Nature 400, 446-449.

Treusch, A. H., Leininger, S., Kletzin, A., Schuster, S. C., Klenk, H. P., and Schleper, C. (2005). Novel genes for nitrite reductase and Amo-related proteins indicate a role of uncultivated mesophilic crenarchaeota in nitrogen cycling. Environ. Microbiol. 7, 1985-1995.

Venter, J. C., Remington, K., Heidelberg, J. F., Halpern, A. L., Rusch, D., Eisen, J. A., Wu, D., Paulsen, I., Nelson, K. E., Nelson, W., Fouts, D. E., Levy, S., Knap, A. H., Lomas, M. W., Nealson, K., White, O., Peterson, J., Hoffman, J., Parsons, R., Baden-Tillson, H., Pfannkoch, C., Rogers, Y.-H., and Smith, H. O. (2004). Environmental genome shotgun sequencing of the Sargasso sea. Science 304, 66-74.

Received: 05 January 2011; accepted: 11 January 2011; published online: 25 January 2011.

Citation: Stein LY and Nicol GW (2011) Grand challenges in terrestrial microbiology. Front. Microbio. 2:6. doi: 10.3389/fmicb.2011.00006

This article was submitted to Frontiers in Terrestrial Microbiology, a specialty of Frontiers in Microbiology.

Copyright (c) 2011 Stein and Nicol. This is an open-access article subject to an exclusive license agreement between the authors and Frontiers Media SA, which permits unrestricted use, distribution, and reproduction in any medium, provided the original authors and source are credited. 